\title{
Analysis and Optimisation of a Production Line Using Discrete Simulation
}

\author{
Fabiane K. Setti ${ }^{(1)}$, Carla A. S. Geraldes ${ }^{(2)}$, João P. Almeida ${ }^{(3)}$, Marcelo G. Trentin ${ }^{(4)}$ \\ (1) Instituto Politécnico de Bragança, Campus de Santa Apolónia, 5300-253 Bragança, Portugal and Universidade \\ Tecnológica Federal do Paraná, Pato Branco, Paraná, Brasil, email: fabisetti@hotmail.com \\ (2) Research Centre in Digitalization and Intelligent Robotics (CeDRI) com sede no ipb, Instituto Politécnico de \\ Bragança, Campus de Santa Apolónia, 5300-253 Bragança, Portugal, and Centro ALGORITMI, Universidade do \\ Minho, Campus de Azurém, 4800-058, Guimarães, Portugal, e-mail: carlag@ipb.pt \\ (3) Research Centre in Digitalization and Intelligent Robotics (CeDRI) com sede no ipb, Instituto Politécnico de \\ Bragança, Campus de Santa Apolónia, 5300-253 Bragança, Portugal, and LIAAD-INESC TEC, Universidade do Porto, \\ Porto, Portugal, e-mail: jpa@ipb.pt \\ (4) Universidade Tecnológica Federal do Paraná, Pato Branco, Paraná, Brasil, email: marcelo@utfpr.edu.br
}

\begin{abstract}
This study presents a simulation-based procedure to analyse a production line of a metalworking company. We use a simulation tool, ProMode ${ }^{\circledR}$ software, to reproduce the existing production line layout of the company best-selling product which represents about $70 \%$ of the total sales. Our purpose is to get information about the existing system behaviour, and to find strategies to increase actual production level to meet the market's demand. Based on an initial simulation model, different production scenarios were proposed and results have shown that it is possible to increase the production level allowing to meet the increasing demand for the product. The following changes in the production system were considered: (i) the use of intermediate stock of work-in-process items, (ii) the introduction of new equipment, and (iii) a mixed strategy where the introduction of new equipment is combined with the use of intermediate stock of work-in-process items. In summary, this research exhibits the flexibility of the simulation technique to address manufacturing problems throughout the creation of different scenarios providing some of the behaviour of the systems allowing the anticipation of final outputs.
\end{abstract}

Keywords: Discrete simulation, manufacturing process, bottleneck 